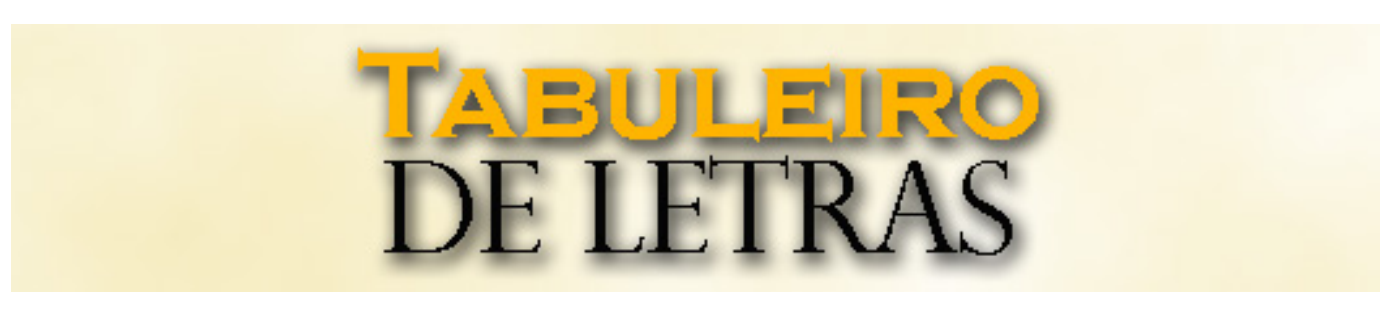

\title{
Ensino-aprendizagem de espanhol como língua estrangeira num cursinho popular voltado para o Enem: contribuições via Linguística Aplicada e Estudos Discursivos
}

\section{Teaching-learning of Spanish as a foreign language in a popular course aimed at Enem: contributions via Applied Linguistics and Discursive Studies}

\author{
Carlos Eduardo da Silva Ferreira ${ }^{1}$
}

\begin{abstract}
RESUMO: O objetivo proposto neste artigo é apresentar questões relacionadas ao ensino de língua espanhola, tendo como foco a preparação dos alunos para o Exame Nacional do Ensino Médio (Enem). Tais questões nasceram do projeto desenvolvido durante o meu Estágio Supervisionado de Prática de Ensino de Língua Estrangeira, juntamente com meu grupo, ocorrido no ano de 2012. Ao mesmo tempo, o espaço aqui oportunizado traz reflexões teóricas entre a Linguística Aplicada e os estudos discursivos. O referido projeto foi aplicado aos alunos de um cursinho pré-vestibular mantido pela Faculdade de Ciências e Letras de Araraquara, na condição de optativo. O minicurso, com carga horária de 30 horas, que foi ministrado por mim e colegas da turma, teve como objetivos 1) possibilitar aos vestibulandos a aproximação de reflexões sobre culturas diferentes e fazer com que eles relacionassem o sistema linguístico-discursivo da língua portuguesa ao sistema da língua espanhola, para tanto utilizando atividades de leitura e interpretação de diferentes tipos de textos escritos em língua espanhola; 2) desenvolver a competência linguístico-discursiva do público-alvo; e 3) preparar o vestibulando para a avaliação do Enem 2012. Ao final do minicurso, o grupo considerou como aspectos positivos as reflexões ocorridas sobre as variedades linguísticas na língua espanhola e as discussões sobre as semelhanças entre a língua materna e a língua estrangeira e ainda as adequações de elementos linguísticos aos diferentes gêneros discursivos estudados.
\end{abstract}

Palavras-chave: Ensino; Língua espanhola; Vestibular; Enem.

ABSTRACT: The purpose of this paper is to present questions related to Spanish language teaching focusing on the students' preparation for Exame Nacional do Ensino Médio (Enem) evaluation. These issues were born of the project developed during my Supervised Internship of Foreign Language Teaching Practice (with my group too), held in the year of 2012. At the same time, the space offered here brings theoretical reflections between Applied Linguistics and discursive studies. This project was applied to the students of a pre-university course maintained by the Faculdade de Ciências e Letras de Araraquara, in the condition of optional class. The 30-hour minicourse, which was taught by me and colleagues in the class, aimed 1) to enable students to approach reflections about different cultures and make them relate the linguistic-discursive system of the Portuguese language to the System of the Spanish language, using for this purpose activities of reading and interpreting different types of texts written in Spanish; 2) to develop the linguistic-discursive competence of the target audience; and 3) to prepare the students for the evaluation of Enem 2012. At the end of the mini-course, the group considered as positive aspects the reflections on Spanish-language linguistic varieties and the discussions about the similarities between the mother tongue and the foreign language and still the adaptations of linguistic elements to the different discursive genres studied.

Keywords: Teaching-learning; Spanish; University entrance exams; Enem

\footnotetext{
${ }^{1}$ Doutorando em Linguística e Língua Portuguesa pela Faculdade de Ciências e Letras da Unesp de Araraquara. Bolsista CAPES. Doutorando no Programa de Pós-Graduação Multiunidades em Ensino de Ciências e Matemática (Pecim), na Unicamp. E-mail: karloseduardoo@yahoo.com.br
} 


\section{Introdução}

O presente texto apresenta questões relacionadas ao ensino de língua espanhola, tendo como foco o trabalho pedagógico aplicado aos estudantes que se preparam para a avaliação do Exame Nacional do Ensino Médio (Enem), no ano de 2012. Tais questões são decorrentes do projeto "Trabalhando Língua Espanhola com foco na avaliação do Enem 2012", desenvolvido durante o término de minha graduação, acontecimento ocorrido no primeiro semestre do corrente ano. O referido projeto foi posto em prática na forma de um minicurso de 30 horas destinado aos estudantes de um cursinho pré-vestibular atendido pela Faculdade de Ciências e Letras de Araraquara na condição de optativo.

Ressalta-se que tanto o projeto quanto o minicurso fizeram parte das atividades de meu "Estágio Supervisionado de Prática de Ensino de línguas estrangeiras: italiano e espanhol". Convém também esclarecer que nessa disciplina, além das regências de aulas, os estagiários elaboram um diário reflexivo de todo o processo do estágio do qual possam utilizar os registros e reflexões para a confecção de um relatório final. Nesse sentido, as atividades de estágio não só proporcionam ao licenciando uma oportunidade de contato prático-imediatista com situações de ensino-aprendizagem em contexto formal de ensino, mas também permitem que sejam planejadas e desenvolvidas várias atividades a partir de conhecimentos adquiridos e discutidos ao longo de sua formação acadêmica. Além disso, trata-se de uma oportunidade para poder pensar criticamente sobre sua prática de sala de aula e sobre a articulação dessas práticas com questões teóricas.

De fato, o projeto “Trabalhando Língua Espanhola com Foco na Avaliação do Enem 2012" nasceu da necessidade de se incluir o ensino de língua espanhola em um cursinho preparatório para o vestibular, especificamente para a avaliação do Enem 2012. É pertinente explicar que o Exame Nacional do Ensino Médio (Enem) é uma prova criada pelo Ministério da Educação e Cultura (MEC) em 1998, para servir como ferramenta avaliativa na medição da qualidade geral do Ensino Médio no País. Nos últimos anos, o Enem começou a ser utilizado também como exame de acesso ao Ensino Superior em universidades públicas brasileiras por meio do Sistema de Seleção Unificado (SiSU). Ademais, o Enem também é feito por pessoas com interesse em ganhar pontos para o Programa Universidade para Todos (ProUni) e, a partir de 2009, passou a servir como certificação de conclusão do Ensino Médio em cursos de Educação de Jovens e Adultos (EJA).

Por outro lado, deve-se considerar também a valorização da língua espanhola no contexto educacional brasileiro, tendo em vista que desde 2005, com a Lei $\mathrm{n}^{\mathrm{o}} 11.161 / 2005$, 
ela passou a integrar as grades curriculares, sendo sua oferta obrigatória nas escolas públicas e privadas do Ensino Médio e ainda pela inserção dessa língua no Enem como item avaliativo possível ao lado da língua inglesa como opções de avaliação em língua estrangeira, a partir de 2010.

Assim, dada a importância crescente da língua espanhola, tanto no ensino regular quanto no Enem, e ainda considerando a importância que esse exame vem adquirindo para o ingresso no Ensino Superior, a discussão sobre como trabalhar a língua espanhola na preparação para esse exame nacional torna-se relevante e procedente. Segundo Kanashiro (2012, p. 28-29), diante desse novo cenário, algumas perguntas devem ser feitas: "Qual a concepção de leitura de textos de espanhol como língua estrangeira subjacente nas provas”? Que tipo de habilidades e conhecimentos o examinando deve demonstrar? Quais modalidades de textos e questões são selecionadas para o exame? E para respondê-las é necessário que sejam fomentadas pesquisas sobre o tema, para que se tenha maior clareza sobre as funções do Enem e também sobre os possíveis efeitos desse exame para as referências curriculares do Ensino Médio.

Certamente tais questões deverão embasar o planejamento de cursos e de materiais didáticos com vistas a preparar o vestibulando para a avaliação do Enem. Nessa perspectiva, o projeto “Trabalhando Língua Espanhola com Foco na Avaliação do Enem 2012" foi desenhado com os seguintes objetivos: possibilitar aos vestibulandos a aproximação de culturas diferentes e fazer com que eles relacionassem o sistema da língua portuguesa ao sistema da língua espanhola, realizando, para tanto, atividades de leitura e interpretação de diferentes tipos de textos escritos em língua espanhola; desenvolver a competência linguístico-discursiva do público-alvo e; preparar o vestibulando para a avaliação do Enem 2012

Em 2009, a prova, que antes visava à avaliação de perfis dos estudantes do Ensino Médio, passou a reforçar, por meio de algumas mudanças, o objetivo de selecionar alunos concluintes da educação básica para a inserção em várias Instituições de Ensino Superior (IES), inclusive nas públicas, algumas estaduais e federais. A partir daquele ano a estrutura da prova sofreu alterações, houve aumento no número de questões e a aplicação do exame foi organizada em dois dias. Além da redação, foram incluídas 45 questões para cada área de conhecimento:

A partir dessa data, a cada ano o Enem tem sido utilizado como artifício de ingresso, de maneira direta, em IES. Nos anos anteriores - e ainda persistente em alguns vestibulares -, 
o exame era utilizado como cofator de cálculo final em vestibulares de faculdades tanto privadas quanto públicas. Nas provas de 2012 em diante, há uma evidente explicitação da função do Enem como vestibular, exaurindo sua centralidade como instrumento avaliativo do Ensino Médio/Básico.

\section{Abordagem Teórica em Pauta}

O ponto de partida desta pesquisa se fundamenta em uma orientação teóricometodológica dentro da Linguística Aplicada voltada ao ensino de língua estrangeira, bem como nas reflexões desenvolvidas pelos estudos dialógicos do discurso.

Apresentamos aqui reflexões teóricas delineadas pelo entrelugar da Linguística Aplicada e dos Estudos discursivos, na medida em que trazemos uma abordagem quantitativo-qualitativa do desenvolvimento de atividades realizadas no projeto em questão.

Tomamos como fundamentação de olhares o entendimento de que nós, seres humanos, fazemos processos representativos/referenciais envolvendo a história da cultura humana, envolvendo os sujeitos sócio-históricos que nos antecederam, conferindo às nossas colocações uma rede de confrontos de ações, gestos e pontos de vista, instaurando a natureza da dialogicidade, a responsividade/respondibilidade conosco e com o outro (alteridade), processo psicossociobiológico o qual chamaremos de "linguagem". Sendo assim, os estudos linguísticos contribuem analiticamente para as discussões sobre valoração de mundo, sobre mecanismos de estabilizações e desestabilizações de discursos em circulações nas inúmeras esferas de atuação na humanidade.

Focalizar os nossos trabalhos a partir do processo interativo exige instaurar um deslocamento. A linguagem é compreendida como repertório, tradução de pensamentos prévio, ponto estável, acabado para a linguagem vista no confronto entre o 'dado' e 'novo', o repetível e o singular. É preciso fazer emergir espaços em nós que sustentem/inspirem a disponibilidade estrutural para a mudança, admitindo-se, portanto, a historicidade da linguagem, a constituição contínua dos sujeitos e o espaço das interlocuções discursivas (FERREIRA, 2015).

Dessa forma, refletir os processos de expressividade humana (os "jogos de linguagem") faz profunda diferença no quesito do fazer científico, pois desdobra a interatividade entre instâncias autor-texto-leitor, articulando vozes, tramando redes discursivas, expondo um horizonte ressignificado pela história de um "eu" na relação ética com seus "outros". 
Para quem se coloca a assumir uma posição dialógica, que inclui não definir de antemão os pontos de chegada e que inclui não definir de antemão os limites do objeto posto em cena, o trabalho com a linguagem é um produto da vida social, a qual não é fixa e nem petrificada. O entrelugar nos paradigmas e nos campos científicos, por exemplo, vem de embates sócio-históricos.

Quando pensamos conceitos bastante difundidos e aceitos pelos cenários de pares na academia, como, por exemplo, o de competência linguístico-discursiva, colocamos no centro linhas de adesão e contra-adesão, de centralização e descentralização. Em seu seminal On Communicative Competence (1972), Dell Hymes apresentou argumentos para defender que o conceito de 'competência' de Chomsky (o falante ideal em uma comunidade de língua homogênea) é, de certo modo, incompleto. Para Hymes, mais do que adquirir as regras formais da língua, os falantes nativos também adquirem outras regras (sociolinguísticas) que podem igualmente ser analisadas e descritas.

Entendemos que todas as classificações e tipologias precisam ser questionadas, pois as atividades do devir, dos acontecimentos nos jogam em vasos comunicantes que coabitam entre sistemas ou contornos limítrofes, ou em pontos. Alguns vão se questionar sobre o emprego - por parte de quem se fundamenta de certa maneira com o quadro reflexivo linguístico-funcional - com termos como "usuário" da língua, ou como compreensões de que o ensino de língua se volta instrumentalmente para a comunicação. De maneira razoável podemos entender pontos estabilizantes nesses trajetos conceituais, mas, na contrapalavra, como num silêncio constitutivo latente, fluem sentidos de fuga que agregam reflexões de movimento dialético - resposta - tal como o da compreensão de que as expressividades linguísticas não são meros instrumentos que os sujeitos a tomam, mas sim sistemas dialógicos que fazem os sujeitos se constituírem enquanto consciência de si, ao mesmo tempo em que são tocadas e, a partir dessa relação, alteradas, ressignificadas a cada momento enunciativo, a cada interação social intersubjetiva.

Bakhtin (BAJTÍN, 1975 apud BUBNOVA, 2011) nos coloca que

[...] toda palavra (enunciado) concreta encontra o objeto que é dirigido ao falado [...], discutindo, avaliando, envolto em uma neblina que lhe faz sombra ou, ao contrário, na luz das palavras alheias já ditas sobre ele. Encontra-se enredado e penetrado por ideias comuns, ponto de vista, avaliações alheias, acentos. A palavra orientada ao seu objeto entra neste meio dialogicamente agitado e tenso das palavras, valorações e acentos alheios, se entrelaça com suas complexas inter-relações, funde-se com umas, repele outras, entrecruza-se com terceiras. (p. 89-90). 
Nessa linha reflexiva, podemos compreender que todo texto (materialização expressiva de discursos: oral, visual, verbivoco, sinal etc.) é atravessado, ocupado, habitado pelo discurso do outro, bem como é possível por meio de diálogos sócio-históricos que confluíram para o acontecimento dele. Assim, podemos vivenciar os constantes diálogos não entre objetos-textos-parados, mas sim entre sujeitos nas mais variadas situações de atividades sociocomunicativas.

\section{Contextualizando nosso Ambiente de Trabalho}

Conforme já pontuado em meu trabalho anteriormente compilado, "a história dos cursinhos pré-vestibulares possui um vínculo necessário com a história dos processos escolares no Brasil” (FERREIRA, 2014, p. 94).

O curso pré-vestibular popular, amplamente denominado como "cursinho", se configura numa estrutura de curso rápido, focado na proximidade de um sujeito prestar algum exame vestibular ou outro processo seletivo. A prestação de informatividade e preparação para os vestibulares/concursos é o eixo orientador destas instituições "paralelas" ao ensino da Escola Básica. Tais cursos são um fenômeno brasileiro da década de 1950, quando a demanda pelas vagas nas universidades brasileiras aumentou. Eram famosos pelo uso de técnicas de memorização, geralmente à base de músicas e rimas, características estas que se tornaram estereótipos e se aplicam comumente entre alguns docentes.

Podemos constatar que no período dos últimos anos houve, na comunidade brasileira, uma intensificação da demanda pelo Ensino Superior (ES) entre os jovens de baixa renda, transformação social que não se isenta de contradições, já que as políticas de expansão perante a privatização do ES brasileiro não oportunizaram o ingresso dos concluintes do Ensino Médio que se vinculam ao ensino público. É na década de 1960 a 1970 que, segundo os dados de Sampaio (2010, p. 57), chegamos a confrontar uma oposição relacionada às matrículas de estudantes no ES num registro em que o crescimento na casa dos $260 \%$ ocorria nas instituições do setor público, enquanto o setor privado tocava o número de mais de $500 \%$. Para termos mais debates sobre os Cursinhos no Brasil interligados a uma história dos rumos educacionais, destaco os interessantes debates colocados por Zago (2008), além dos autores já citados.

Situando o ambiente em que o nosso projeto foi desenvolvido, o "Ensinando língua espanhola com foco no Enem 2012" se realizou em um cursinho vinculado à Faculdade de 
Ciências e Letras de Araraquara, a Unesp: o "Cursinho Geração". Trata-se de um projeto piloto que vem sendo desenvolvido desde 2009 cujo serviço de extensão universitária ganhou espaço físico de atuação na Chácara Sapucaia, pertencente à instituição da Unesp. Nos anos anteriores, o Cursinho atuava em algumas escolas da rede pública estadual - São Paulo -, como Lysanias de Oliveira Campos, Vitor Lacorte, Ergília Micelli e Sérgio Speranza ${ }^{2}$. Com uma ampliação de sua atuação, a partir de 2012 o Cursinho ganha uma sede e estende seu projeto para todas as escolas de Araraquara e microrregião, atendendo, por exemplo, ao público de Américo Brasiliense.

Trabalha-se ali Língua Portuguesa ${ }^{3}$, Matemática, História, Geografia, Biologia, Química, Física e a optativa do Espanhol. São as disciplinas nas quais os alunos encontraram maior exigência nos vestibulares. Quaisquer necessidades de estudos paralelos ou especificidades de vestibulares são incorporadas juntamente em aulas extras.

No ano de 2012, o Cursinho funcionou de segunda a sexta na Chácara Sapucaia, das 14h às 17h30. Às quintas-feiras eram destinadas a atividades de um ciclo literário - outro projeto - que ocorre ali e, especialmente para a optativa do Espanhol, a realização dessas aulas se dá, como já dito, nas quartas-feiras das $17 \mathrm{~h}$ às $18 \mathrm{~h} 30$.

Aos sábados, o Cursinho tinha sua realização nas dependências da FCLAr, tendo uma programática específica com os alunos desse dia - que em parte são os que fazem durante a semana, porém com outros alunos. Nosso projeto de Espanhol não contempla esse dia, porém houve algumas aulas de Língua Espanhola durante esses finais de semana.

\section{a) Nosso Projeto}

Em 2010, com o replanejamento da avaliação do Enem, a língua espanhola, que até então não era uma parte integrante dessa prova, passa a ser um item avaliativo possível, pois há uma opção da escolha entre a Língua Espanhola e a Língua Inglesa.

Paralelamente a essa normatização, o ensino regular das escolas públicas no Brasil é também reorganizado na área de Língua Estrangeira, tendo o espanhol como uma das exigências da "grade" curricular. É a partir dessa reforma que o ensino público se vê obrigado a ter aulas de espanhol.

2 Estas escolas se localizam, respectivamente, nos bairros Vila Xavier, São José, Selmi Dei e Parque São Paulo. A implantação se deu nessas escolas, a fim de promover uma maior integração entre os espaços abertos por elas com os outros contextos sociais dos alunos. O projeto do Cursinho se insere na realização do "Projeto Novas Tecnologias e Linguagens para o Ensino Médio e Fundamental”, com vínculo à FCLAr - UNESP.

3 Área subdividida em Literaturas - brasileira e portuguesa -, Gramática do Português e Leitura, Produção e Interpretação de Textos. 
Como parte de nossa Prática de Língua Estrangeira decidimos trabalhar com os alunos do Cursinho pré-vestibular “Geração", projeto de extensão universitária do Núcleo de Ensino de Araraquara (NEAR) da Faculdade de Ciências e Letras de Araraquara - Unesp. Para tal, desenvolvemos aulas de língua espanhola focando na leitura e interpretação de textos escritos dessa língua, contribuindo também na competência linguístico-discursiva dos alunos, aplicando conhecimentos da Teoria do Texto.

b) Motivação

Pontuamos a seguir os principais objetivos do nosso projeto:

- Aplicar um curso voltado para a interpretação textual - na escrita - em Língua Espanhola. Uma oportunidade de se preparar para a avaliação do Enem 2012, além de outras avaliações que possuam Língua Espanhola como elemento-teste;

- Aproximar o aluno de culturas diferentes da nossa;

- Fazer relações entre o sistema da Língua Portuguesa com o sistema da Língua Espanhola;

- Trabalhar com tipos textuais da língua escrita, com noções críticas do que é um texto;

- Abrir um espaço de discussão linguística a respeito escolhas de línguas estrangeiras para avaliações.

c) Metodologia

Fizemos um levantamento na sala regular do Cursinho, entre aqueles que estavam dispostos a prestar o Enem 2012, a respeito da escolha da língua estrangeira a ser avaliada. Essa pesquisa serviu para demonstrarmos a relação do tempo dedicado ao estudo de língua estrangeira e a escolha da língua para o exame, procurando evidenciar os motivos dos alunos para tal opção.

A respeito do desenvolvimento das aulas afunilamos nosso trabalho na interpretação dos tipos textuais via escrita, que estão presentes em questões elaboradas pelo Enem. Para isso, introduzimos os alunos, primeiramente, ao universo interacional da Língua Espanhola, demonstrando um pouco de sua multiplicidade. Estudamos a proximidade da Língua Portuguesa com a Língua Espanhola, por meio da Linguística Histórica, e trabalhamos em seguida a ideia de "texto" contida na Teoria do Texto. Encerramos assim nossas atividades com análises das questões do Enem dos anos anteriores, com uma avaliação do minicurso 
dado e com um debate aberto para dúvidas, questionamentos e outros pontos passíveis de discussão.

Em todo o decorrer das atividades, propusemos questões reflexivas sobre a educação de língua estrangeira no Brasil com as relações de exigências avaliativas em exames vestibulares.

\section{d) Nossa Pesquisa Inicial}

Em primeiro lugar, mantivemos contato com os alunos do "Cursinho Geração", para sabermos sobre as opções de Língua Estrangeira e também fazermos uma reflexão sobre como estas são eleitas pelos alunos, de acordo com o estudo linguístico dos discentes, formando assim um percentual que indicasse fatores possíveis para tais escolhas.

A seguir, apresentamos essa nossa pesquisa inicial:

Situação: Alunos do Cursinho Geração, todos advindos de escolas públicas da região e microrregião de Araraquara.

Perguntas:

$>\quad$ Qual será sua escolha em relação à língua estrangeira (Inglês ou Espanhol) para a realização do Enem?

$>\quad$ Você já teve sistematizações em aulas dessas línguas? Ou estuda como autodidata?

Dados sobre os alunos

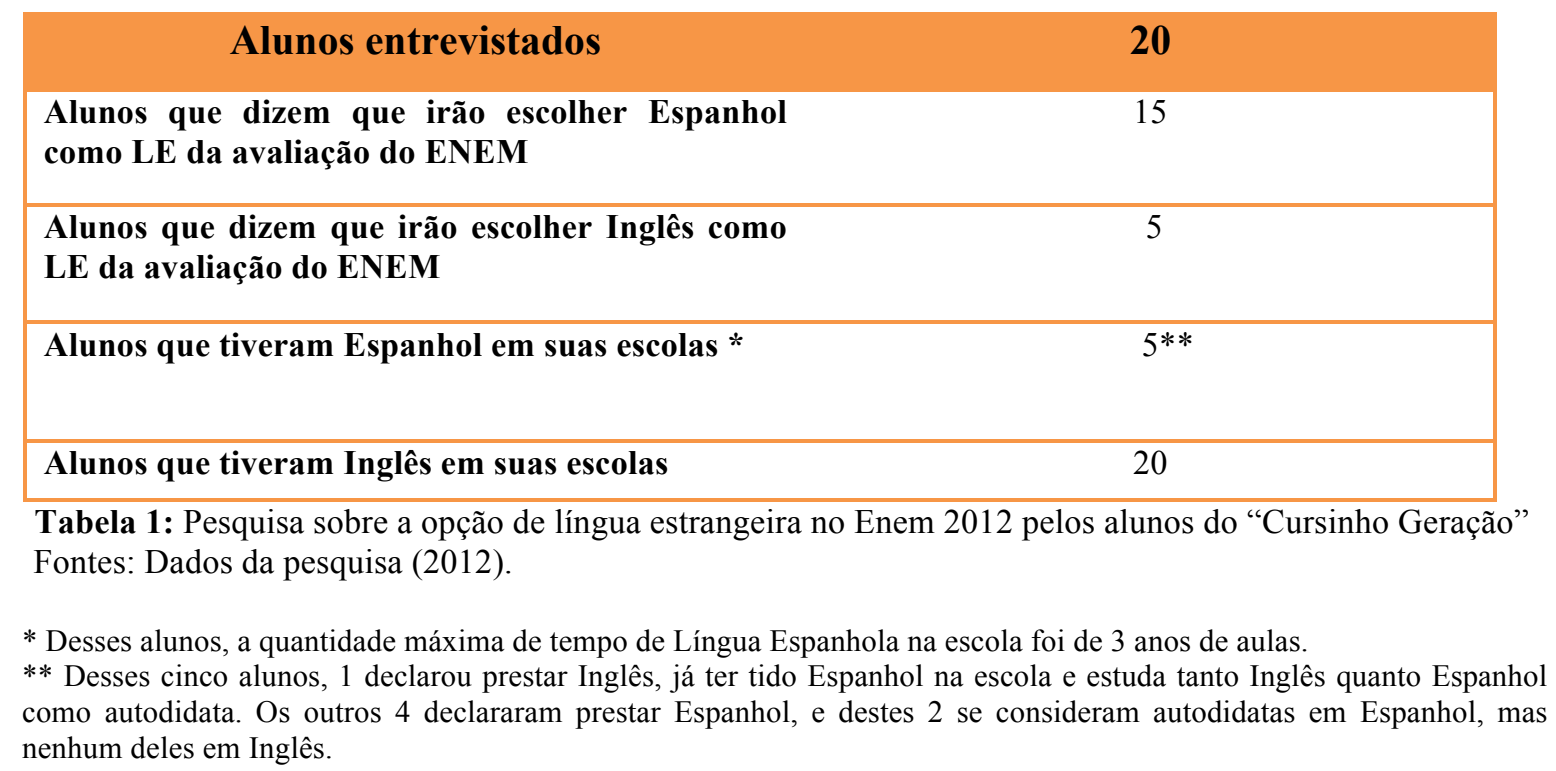

e) Apontamentos sobre a Pesquisa 
Apesar de o número de alunos ser maior em relação à sistematizações de aulas de inglês oferecidas pelo Estado, a escolha por espanhol na realização da prova é quantitativamente maior. Esse fato nos revela uma insegurança na escolha da língua inglesa, já que mundialmente podemos dar a ela o status linguístico de língua franca.

O motivo da semelhança estrutural da língua escrita é um dos fatores que motivam os alunos a escolherem a língua neolatina em vez da anglo-saxã. Isso é verificável no dado a seguir, obtido na pergunta aos 15 que anunciaram fazer a avaliação de Espanhol:

$>$ Por que escolher espanhol e não Inglês, já que o inglês está na grade escolar e possui status de força cultural-política na ordem mundial?

Resposta em comum acordo:

\section{Semelhança com a língua portuguesa (escrita)}

Essa realidade dos alunos foi o ponto de partida para a realização de nossas atividades.

Com isso, introduzimos os alunos ao universo interacional da Língua Espanhola, demonstrando um pouco de sua multiplicidade. Estudamos a proximidade da Língua Portuguesa com a Língua Espanhola, por meio da Linguística Histórica. Considerando que a semelhança está no registro escrito, trabalhamos a ideia de texto contida na Teoria do Texto.

\section{f) Aplicação do Projeto}

Situados no ambiente de aplicação e desenvolvimento do nosso projeto conjuntamente com a pesquisa inicial -, o grupo se reuniu para delinear abordagens e sequencializações das aulas a serem aplicadas com os alunos. Mostraremos a seguir como se esquematizaram nossas aulas, de acordo com as reflexões já expostas.

São plano de aulas para 10 aulas, ocorrentes no $1^{\circ}$ semestre:

\section{Aula 1 - E o mundo fala em espanhol? Usos e variedades da Língua Espanhola}

- Apresentação do curso e motivação.

- Discussões com os alunos sobre os dados da quantidade entre eles que utilizarão o espanhol para as provas de vestibular.

- Quais países no mundo falam o espanhol - seja como língua materna ou estrangeira? 
- Exemplos das variedades faladas do espanhol e adoção de uma delas por parte dos alunos, para possíveis leituras realizadas em sala, sempre lembrando que o foco está na leitura, interpretação de textos, aquisição de vocabulário e cultura.

Nessa aula apresentamos o curso e seus objetivos além de levantarmos dados acerca da quantidade de alunos que se utilizariam do espanhol para as provas de vestibulares. Além disso, mostramos aos discentes os países que possuem a língua espanhola como oficial.

Cada um dos quatro professores tinha preferências diferentes quanto à variedade do espanhol que falavam, e dessa maneira pudemos expô-las aos alunos, dando-lhes a oportunidade de escolher a que mais apreciassem, ainda que o foco das aulas ministradas não fosse a oralidade.

Referência da Aula 1:

GARCÍA, María de los Ángeles; HERNÁNDEZ, Josephine Sánchez. Español sin fronteras. vol 1. São Paulo: Scipione, 2002.

\section{Aula 2 - Uma história do latim: visões da História da Língua Portuguesa e da Língua Espanhola}

$\mathrm{Na}$ segunda aula apresentamos um panorama histórico das línguas neolatinas, citando suas possíveis origens, suas semelhanças e até mesmo expondo uma certa lógica em relação à estrutura de algumas palavras, por meio da comparação entre as modificações sofridas pelos vocábulos das línguas espanhola, portuguesa no decorrer da ramificação da língua latina.

Referência da Aula 2:

GOUlART, A.T. e SILVA, O.V. Estudo dirigido de gramática histórica e teoria da literatura. São Paulo: Ed do Brasil S.A., 1974

\section{Aula 3 - Estruturas linguísticas do sistema do espanhol: relações entre as línguas portuguesa e espanhola}

Essa aula consistiu em uma abordagem estrutural da língua espanhola. Explicamos as semelhanças entre as construções frasais no português e no espanhol, comparamos o uso de pronomes, a formação de plural e a flexão dos verbos. Para finalizar a aula expusemos o conceito de heterogenéricos e colocamos exemplos de palavras comumente utilizadas que possuem esse aspecto.

Referência da Aula 3:

FANJUL, Adrián (Org.). Gramática y práctica de español para brasileños. São Paulo: Moderna/Santillana, 2005.

Aula 4 - Cultura hispano-americana: foco nos textos escritos 
Essa aula teve como escopo um conto de Júlio Cortázar, sua biografia e aspectos da cultura e da variedade linguística da Argentina, além de contextualizarmos referenciais histórico-literários latino-americanos.

Referências da Aula 4:

http://www.librosgratisweb.com/html/cortazar-julio/casa-tomada/index.htm http://pt.wikipedia.org/wiki/Am\%C3\%A9rica_espanhola

www.rae.es

www.wordreference.com

\section{Aula 5 - Trabalhando com o léxico do espanhol: foco nos heterossemânticos}

A aula teve como tema os heterossemânticos. Explicamos o conceito dessa relação lexical e utilizamos uma narrativa que possuía uma quantidade grande de falsos cognatos, a fim de que fosse incrementado o vocabulário dos alunos, além de fazê-los atentar ao contexto da história narrada e obter uma interpretação razoável do que foi lido. Para finalizar a aula, apresentamos aos discentes alguns conectores frasais e suas funções dentro do texto.

Referências da Aula 5:

BUENO, F. S. Minidicionário da língua portuguesa São Paulo: FTD:LISA, 1996. www.rae.es

www.wordreference.com

www.priberam.pt/DLPO/

http://ec.europa.eu/translation/bulletins/puntoycoma/100/pyc10023_es.htm

http://jeff-interlinguas.blogspot.com.br/2009/02/espanhol-heterosemanticos.html

\section{Aula 6 - Os textos: a identidade do sujeito (reflexões no ensino de língua estrangeira, com foco em espanhol)}

Para iniciarmos essa aula, expusemos o conceito linguístico de "texto". Refletimos, a seguir, sobre como se relacionam a forma e o conteúdo desses textos com sua produção e a recepção desenvolvendo, assim, reflexões sobre "contexto", com base nas leituras da Linguística Textual - especificamente em Koch, com interfaces em Maingueneau. Para isso discutimos acerca de como os sujeitos, indivíduos sociais que vivenciam determinada passagem histórica, influenciam suas produções textuais, bem como a recepção delas por meio de diversas visões de mundo. Para finalizar a aula, fizemos a leitura de uma dissertação, em espanhol, produzida por um dos professores, a fim de demonstrar o que foi refletido e discutido anteriormente.

Referências da Aula 6:

KOCH, I. G. V. A coesão textual. São Paulo: Contexto, 2005. 
Estratégias pragmáticas de processamento textual. In: Caderno de estudos linguísticos. Campinas (30): Edunicamp, 1996, p.35-42.

\section{Aula7 - Comunicação textual: foco nos textos escritos em Língua Espanhola}

Nessa aula refletimos sobre gêneros/tipos textuais e como a forma e o conteúdo auxiliam o leitor no reconhecimento das diversas variedades de textos, fazendo instigações às leituras de textos (concepção plural) pelos alunos.

Referência da Aula 7:

TERRA, Ernani; DE NICOLA, José. Português: de olho no mundo do trabalho. São Paulo: Scipione, 2006.

\section{Aula 8 - Gêneros textuais}

Com base na teoria da aula anterior, trouxemos textos distintos em língua espanhola (poema, verbete de dicionário, música e dissertação), com o objetivo de que os alunos percebessem a diferença (forma, funcionalidade e contextualização) entre eles.

Referências da Aula 8:

ttp://es.wikipedia.org/wiki/Antonio_Machado

www.rae.es

http://letras.mus.br/joan-manuel-serrat/538442/

http://www.poemas-del-alma.com/antonio-machado-caminante-no-hay-camino.htm

\section{Aula 9 - Gêneros discursivos}

Novamente, com base nas teorias discutidas na aula sete, apresentamos aos alunos trechos de diversos gêneros textuais em língua espanhola, a saber: conto, texto bíblico, descrição, trava-línguas e piada. A finalidade aqui, como já vem sendo desenvolvida nas aulas passadas, é investir nas discussões que ligam a forma textual, o conteúdo dos significados linguísticos e a contextualização discursivo-funcional, para refletirmos como o gênero influencia nas interpretações textuais.

O trabalho com os gêneros discursivos no ensino tem ganhado sobre-elevações nos diversos documentos oficiais brasileiros. O gênero discursivo, longe de se igualar com o gêneros estilístico-retóricos lírico, épico e dramático (canônicos nos estudos literários), operam no direcionamento de dar um sistema de restrições do dizer, ou seja, são modelamentos dos modos de dizer, inscritos numa rede de circulação.

Os gêneros discursivos se ligam a maneiras composicionais que operam no modo da seleção e combinação dos dizeres. Compreender esse empreendimento é compreender as formas e as sensações de valores enunciativos delimitantes por este sistema sócio- 
historicamente construído. Trazer gêneros discursivos aos estudos linguísticos é possibilitar um florescer de modos de se colocar nos textos.

Referências da Aula 9:

http://www.encuentos.com/cuentos-cortos/la-piedra-en-el-camino-cuentos-para-pensarcuentos-breves-reflexiones/

http://lbla.bibliaparalela.com/john/14.htm

$\mathrm{http}: / /$ www.mysteryperu.com/esp/cu_inca_trail.html

http://www.soespanhol.com.br/conteudo/Entretenimento_trabalenguas.php

http://www.soespanhol.com.br/conteudo/Entretenimento_piadas1.php

\section{Aula 10 - Analisando as questões de Língua Espanhola do ENEM 2010 e 2011}

Nessa última aula programada propusemos uma avaliação que consistia em responder às questões de língua espanhola presentes nos cadernos dos anos 2010 e 2011 do ENEM. Fizemos também uma pequena revisão acerca das teorias e conceitos vistos ao longo do curso.

Referência da Aula 10:

Exame Nacional do Ensino Médio, anos 2010 e 2011.

\section{$\underline{\text { Reflexões: }}$}

O que procuramos evidenciar em nossa proposta se explicita basicamente por duas vertentes interfluentes:

1) Reflexão linguística - discussões sobre língua, literatura e cultura espanhola; foco no input linguístico;

2) Reflexão linguístico-discursiva - com a Teoria do Texto colocamos em discussões o posicionamento interpretativo de um texto - em uso latu -, relativizando o posicionamento dos sujeitos diante da expressão textual: propostas da inserção dos alunos no processo de inteligibilidade de um texto.

\section{g) Análise do Minicurso}

Numa escala de $\mathbf{0}$ a $\mathbf{5}$ - em que 0 é o menor valor a se pontuar a respeito de uma das seguintes notações, e 5 é o valor máximo -, avaliamos alguns fatores do processo ensinoaprendizagem, para que pudéssemos refletir sobre as nossas atuações na sala de aula, com a movimentação ideológica que a aula nos proporciona. 


\begin{tabular}{|c|c|c|}
\hline Dado a se avaliar & $\begin{array}{c}\text { Avaliação (média) pelos } \\
\text { professores }\end{array}$ & $\begin{array}{c}\text { Avaliação (média) pelos } \\
\text { cursandos }\end{array}$ \\
\hline $\begin{array}{l}\text { Interesse e aproveitamento pelo } \\
\text { minicurso (pelos professores em } \\
\text { ministrar as aulas / entre os } \\
\text { alunos em diálogos nas aulas) }\end{array}$ & 4 & 5 \\
\hline $\begin{array}{l}\text { Nível de conhecimento prévio } \\
\text { (dos alunos) }\end{array}$ & 3 & 4 \\
\hline $\begin{array}{lll}\text { Interação } & \text { entre } & \text { aluno- } \\
\text { professor(es) } & & \end{array}$ & 5 & 5 \\
\hline Interação entre aluno-aluno & 4 & 4 \\
\hline $\begin{array}{lll}\text { Interação } & \text { entre } & \text { aluno- } \\
\text { coordenação } & & \end{array}$ & 5 & 5 \\
\hline Expectativas alcançadas & 5 & 4 \\
\hline
\end{tabular}

Tabela 2: Levantamento avaliativo das aulas ministradas: dados dos professores e dos alunos Fonte: Dados da pesquisa (2012)

h) Análise da Aplicação e do Desenvolvimento dos Objetivos Propostos e dos Objetivos Atingidos.

O projeto do minicurso tinha como objetivo aproximar e promover uma integração dos vestibulandos a culturas diferentes, fazendo com que eles relacionassem o sistema da língua portuguesa com o sistema da língua espanhola e utilizassem, para isto, atividades com diferentes tipos textuais da língua escrita. Ademais, buscava-se ampliar a "visão de mundo" dos alunos, ao refletirem sobre questões linguísticas, e de prepará-los para a avaliação do Enem 2012 e, consequentemente, para outras avaliações que adotem o espanhol como elemento-teste.

Tendo em vista os objetivos propostos acima, configuramos ter atingido plenamente todos os objetivos. É importante salientar que, ao prepararmos os estudantes para a prova do Enem 2012, em todas as aulas do minicurso houve reflexões sobre variações linguísticas na própria língua espanhola, assim como existem na língua materna. Isto é dito no sentido de corroborarmos as discussões sobre semelhanças entre a língua materna e a língua estrangeira, a fim de interagirmos sobre a questão do fenômeno da linguagem, além da noção da situação 
linguístico-discursiva com as correlações entre as adequações de elementos linguísticos aos gêneros do discurso utilizado.

i) Análise da Metodologia, Procedimentos e Estratégias de Ensino empregadas durante o Minicurso

No minicurso não houve a escolha de um material didático específico e fixo. Os materiais utilizados, em sua maioria, foram escolhidos de acordo com os temas das aulas, com o conhecimento acumulado dos estagiários e baseados no domínio da língua espanhola dos alunos inscritos no curso. Os materiais adotados já foram citados no item $\mathbf{5}$ da Metodologia.

De acordo com o projeto aqui descrito, tínhamos a intenção de desenvolver e despertar nos alunos o interesse pela língua espanhola, além de fazê-los compreender textos de diversos gêneros discursivos. Para tanto, foram utilizados materiais paradidáticos como o jornal argentino El país, atividades com poesia, contos e crônicas que visavam traçar semelhanças e diferenças - tanto fonéticas quanto semânticas - entre o português e o espanhol.

A quarta aula dada pelo grupo tinha como tema "Estruturas linguísticas do sistema do espanhol: relações entre as línguas portuguesa e espanhola". Nessa aula, foi passada aos alunos a poesia $A$ un general, de Julio Cortázar, para que os aprendizes tivessem contato com língua espanhola e percebessem que na sua estrutura há muitas semelhanças, principalmente semânticas, com a língua portuguesa. Pudemos perceber, depois dessa aula, que os alunos se sentiram mais seguros ao interpretar textos, pois adquiriram mais confiança ao afirmar o significado das palavras.

Tendo em vista que a prática oral também está intrinsecamente ligada às habilidades que devem ser desenvolvidas no ensino de língua estrangeira, nessa mesma aula percebemos que os alunos ficavam constrangidos quando pedíamos a eles que lessem, individualmente, em voz alta um determinado trecho da poesia. Para sanar essa atitude, achamos pertinente que os alunos lessem simultaneamente, junto com os estagiários, a poesia. Esse modo de desenvolvimento do ato da leitura fez com que os alunos se sentissem mais à vontade e que, nas aulas seguintes, essa prática foi desenvolvida sem constrangimento e de forma individual.

A forma de avaliação que achamos mais conveniente ao minicurso foi um simulado da prova do Enem. Seguindo o pedido dos alunos e tendo em vista o objetivo do projeto, a avaliação foi feita com base nas provas anteriores do Enem, para que ficasse mais próxima ao que o aprendiz vai enfrentar no dia da avaliação desenvolvida pelo MEC. 
Essa avaliação conseguiu, em partes, alcançar o objetivo que nós, estagiários, gostaríamos. Com o resultado das avaliações em mão, imaginamos que os alunos já estariam capacitados para fazer uma prova que contivesse um vocabulário mais amplo e com textos mais complexos.

j) Dificuldades encontradas durante a realização do estágio (desde a confecção do projeto até a regência).

Quando começamos a fazer o projeto, não encontramos muitas dificuldades. Dividimos as aulas por assuntos, de forma que ao decorrer do minicurso eles iam sendo encadeados e relacionados. Nenhuma das aulas ministradas foi pensada de forma individual, isolada, assim como os conteúdos. Porém, ao começarmos a regência, vimos que não conseguiríamos abordar todos os assuntos que imaginávamos, por conta do tempo disponível e por adentrarmos as necessidades dos alunos, de modo que acabamos dando ênfase para certos assuntos e menos prioridades para outros. No entanto, pretendemos continuar a desenvolver esse projeto no próximo semestre, de forma independente dos compromissos gerenciados pelo estágio.

1) Avaliação do minicurso de um modo geral para o público-alvo e para os estagiários envolvidos.

Avaliamos que os alunos participantes do minicurso estavam interessados, tanto nos temas definidos para as aulas quanto no objetivo principal do minicurso: adquirir conhecimento de língua espanhola para que eles possam futuramente utilizá-lo na realização de provas que avaliem tal língua.

Todos os alunos que frequentaram as aulas cursavam, no período diurno, o Ensino Médio regular em escolas públicas da região de Araraquara. Portanto, logo que saíam de suas aulas regulares de Ensino Médio, eles se dirigiam à Chácara Sapucaia (lugar onde ocorreu o minicurso), para assistir às aulas do cursinho "Geração". A maioria dos estudantes, depois da aula de espanhol, no período noturno, se dirigia à Escola Técnica - próxima à chácara - para frequentar cursos profissionalizantes. Desse modo, vimos nos alunos um grau muito alto de dedicação e comprometimento com o estar na aula para aprender.

Esse panorama da realidade dos alunos contribuiu muito para a realização do curso ministrado por nós, estagiários. Houve, na relação entre estagiário e alunos, muita cooperação 
e troca de experiência, tanto no âmbito do conhecimento adquirido por nós durante os três anos de aula na faculdade de Letras quanto no âmbito pessoal, por já termos passado pela mesma situação no período pré-vestibular.

A experiência como estagiários terá grande importância para a nossa formação profissional, tendo em vista a realização da prática de regência. O processo de elaborar um projeto, fazermos planos de aulas, entrarmos em contato com os alunos, verificarmos qual a realidade desses alunos e colocar em prática conceitos trabalhados durante a faculdade, por meio das aulas ministradas, foi uma maneira de afirmarmos o que imaginávamos sobre a profissão de professor de língua estrangeira.

No grupo, houve aqueles que afirmaram seu gosto pela prática docente e outros que viram nessa prática uma forma de afirmação de outras vertentes proporcionada pela Faculdade de Letras com Habilitação em Espanhol. De todo modo, percebemos uma grande contribuição do estágio supervisionado nas nossas carreiras profissionais.

\section{In-conclusões}

Diz o pensamento do Círculo de Bakhtin que o mundo que cerca os sujeitos - que “nos" cerca - está repleto de vozes de outras pessoas. Podemos entender que vozes são palavras no sentido de ditos "enunciados", de dizeres ecoados pelas tramas da interação cultural, de formações valorativas marcadas em lugares sociais. As vozes articulam imagens de sujeitos formadas ao longo da história da vida com a ideia de autoria, de enunciador: imagens de si mesmo de um sujeito, imagens de si na perspectiva que um sujeito interpreta que seu(s) outro(s) tem (têm) de si, e de imagens que um sujeito tem de seu(s) outro(s). Nesse jogo reflexivo e refratário, o que se instaura nos discursos das vivências são estabilizações de um efeito looping espiralado de produção de sentidos e de movimentação de identidades/ pertencimento.

O campo de debates da Didática de/no ensino-aprendizagem de Língua Estrangeira é um espaço potente para o desabrochar de sensibilidades linguísticas. E, por meio de tomadas e retomadas com os objetos materiais de interação linguajeira, as sutilezas do amadurecimento sociocognitivo vão se desenhando nos jogos despolarizantes da interdisciplinaridade. Fios discursivos se embaraçam em nós, convidando-nos a enovelarmos tramas em nós mesmos. 
Referências

BAJTÍN. M. M. Problemas Literarios y Estéticos [en ruso]. Moscú: Judozhestvenaia Literatura, 1975.

BUBNOVA, Tatiana. Voz, sentido e diálogo em Bakhtin. In: Bakhtiniana, São Paulo, 6 (1): 268-280, Ago./Dez. 2011. Versão para o português: Roberto Leiser Baronas e Fernanda Tonelli.

FERREIRA, Carlos Eduardo da Silva. O vestibular é assim!: análise discursiva em propagandas de cursinhos pré-vestibulares na cidade de Araraquara (2013). Cadernos CIMEAC - v. 4, n. 1, 2014. Ribeirão Preto-SP, Brasil.

O Discurso sobre a Aula de Matemática: articulando vozes na revista Nova Escola. Dissertação (Mestrado em Linguística e Língua Portuguesa) - Unesp, Araraquara-SP. 2015.

SAMPAIO, Helena. Ensino Superior no Brasil: o setor privado. São Paulo: Hucitec/FAPESP, 2000.

ZAGO, Nadir. Cursos pré-vestibulares populares: limites e perspectivas. In: Perspectiva. Florianópolis, v. 26, n. 1, 149-174, jan./jun. 2008. 